\title{
Ferrite multiphase/carbon nanotube composites sintered by spark plasma sintering
}

\author{
Xiaobing ZHOU, ${ }^{\dagger \dagger}$ Young-Hwan HAN, ${ }^{*}, \dagger \dagger$ Yongqiang ZHANG, Qian WANG, Jie ZHOU, \\ Lu SHEN, Tongming HUANG, ${ }^{* *}$ Weiming PAN, ${ }^{* *}$ Changshu XIANG, ${ }^{* * *}$ Huiping TANG, ${ }^{* * *}$ \\ Jaehyung LEE, ${ }^{, \dagger \dagger}$ So Ik BAE, ${ }^{*}$ Dong-Yeon LEE ${ }^{* * * *}$ and Qing HUANG ${ }^{\dagger}$ \\ Ningbo Institute of Materials Technology and Engineering, Chinese Academy of Sciences, \\ Ningbo, 315201, People's Republic of China \\ ${ }^{*}$ School of Materials Science and Engineering, Yeungnam University, Gyeongsan, Republic of Korea \\ ${ }^{* *}$ Institute of High Energy Physics Chinese Academy of Sciences, Beijing, 100049, People's Republic of China \\ ${ }^{* * *}$ State Key Laboratory of Porous Metal Materials, Northwest Institute for Nonferrous Metal Research, Xi'an 710016, China \\ ${ }^{* * * *}$ School of Mechanical Engineering, Yeungnam University, Gyeongsan, Republic of Korea
}

Ni-Carbon nanotube (CNT)- $\mathrm{Ni}_{0.5} \mathrm{Zn}_{0.5} \mathrm{Fe}_{2} \mathrm{O}_{4}$ multiphase composites were sintered by spark plasma sintering (SPS) technique. $\mathrm{Ni}$ nanoparticles were in-situ formed due to the localized carbothermal reduction by CNTs and well distributed between grain boundaries in the composites. The electrical conductivity of the resultant multiphase composites was strongly dependent on the weight percentage of CNTs. In the SPS process, CNTs acted as "heating source" and improved the consolidation of the composites. The results indicate that the introduction of the CNTs can promote the sintering kinetics of the ferrite ceramics. However, the grain growth kinetics has been inhibited by SPS and the grain size becomes finer.

(C2014 The Ceramic Society of Japan. All rights reserved.

Key-words : Multiphase, Spark plasma sintering, Carbon nanotube

[Received March 30, 2014; Accepted June 15, 2014]

\section{Introduction}

$\mathrm{Ni}-\mathrm{Zn}$ ferrites are excellent core materials for microwave devices, power transformers in electronics, rod antennas and $\mathrm{read} /$ write heads for high speed digital tape, etc. and they have been widespread employed in these areas for their good microwave absorbing performance, high resistivity, low magnetic coercivity and high Curie temperature. ${ }^{1-5)}$ Since their discovery by Iijima in 1991, ${ }^{6}$ CNT incorporated ceramic composites have been widely investigated, and a large number of experimental results has shown that appropriate levels of CNT doping can improve the properties of matrix, such as the mechanical properties, the electrical conductivity and the electromagnetic wave absorption, etc. ${ }^{7-12)}$ Due to the higher Snoeks's limit, the metallic soft magnetic material of Ni nanoparticles have better microwave absorption compared with ferrite absorber. ${ }^{13), 14)}$ Zhang X. F. et al. ${ }^{15}$ ) investigated the microwave absorption properties of the carbon-coated $\mathrm{Ni}$ nanocapsules. The results showed that the bandwidth with a reflection loss less than $-10 \mathrm{~dB}$ is from 11.2 to $15.5 \mathrm{GHz}$ and the maximum reflection loss is $32 \mathrm{~dB}$ at $13 \mathrm{GHz}$ with $2 \mathrm{~mm}$ thickness layer. To achieve broad-frequency microwave absorption, one must take advantage of three major attenuation mechanisms: conductivity loss, dielectric loss and magnetic loss. Therefore it is promising that incorporate both CNTs (conductive-loss phase) and Ni metal (magnetic-loss phase) into ferrite materials (both magnetic-loss

\footnotetext{
Corresponding author: Q. Huang; E-mail: huangqing@nimte. ac.cn

† Corresponding author: J. Lee; E-mail: jhlee@yu.ac.kr

tit These authors contributed equally to this work.
}

and dielectric-loss mechanism) to improved electromagnetic properties of ferrite composites. The spark plasma sintering (SPS) method is an advanced technology for manufacturing ferrite. Compared with conventional sintering method, SPS can promote the sintering kinetics and shorten the sintering time at lower temperature. ${ }^{16)}$ In order to avoid or minimize the degradation of CNT network formed in the composite ceramics and to preserve structural integrity of CNTs, SPS technique was used to fabricate $\mathrm{CNT} / \mathrm{Ni}_{0.5} \mathrm{Zn}_{0.5} \mathrm{Fe}_{2} \mathrm{O}_{4}$ bulks in the present work. Ni nanoparticles were also synthesized and evenly distributed in the composites through in-situ carbothermal reduction approach. The phase composition, microstructure and electrical conductivity were investigated.

\section{Experimental procedure}

Multi-walled CNTs (diameters: 50-60 nm, length: 2-10 $\mu \mathrm{m}$, purity of 95\%) were purchased from Shenzhen Nanoport Ltd. Co. (China). $\mathrm{Ni}\left(\mathrm{NO}_{3}\right)_{2} \cdot 6 \mathrm{H}_{2} \mathrm{O}(98.5 \%), \mathrm{Zn}\left(\mathrm{NO}_{3}\right)_{2} \cdot 6 \mathrm{H}_{2} \mathrm{O}(98.5 \%)$, $\mathrm{Fe}\left(\mathrm{NO}_{3}\right)_{3} \cdot 9 \mathrm{H}_{2} \mathrm{O}(98.5 \%)$ and Sodium lignin sulfonate (SLS) (99\%) were purchased from Aladdin Industrial Corporation (China). CNT/ $\mathrm{Ni}_{0.5} \mathrm{Zn}_{0.5} \mathrm{Fe}_{2} \mathrm{O}_{4}$ composite powders were sintered by SPS technique, using the HDP25 Type SPS furnace (FCT System Gmbh, Germany). Ni/CNT/ $\mathrm{Ni}_{0.5} \mathrm{Zn}_{0.5} \mathrm{Fe}_{2} \mathrm{O}_{4}$ multiphase ceramics were synthesized through in-situ carbothermal reduction method. The important sintering parameters were used as follows: $35 \mathrm{MPa}$ of applied pressure, heating rate of $100^{\circ} \mathrm{C} / \mathrm{min}$, target temperature of $800^{\circ} \mathrm{C}$, holding time of $5 \mathrm{~min}$, and cooling rate of $30^{\circ} \mathrm{C} / \mathrm{min}$.

\section{Results and discussion}

Figure 1 illustrates the SEM micrographs of the fracture 
surface of samples with different CNT contents. With the increase in the amounts of CNTs, the average grain size of the composite ceramic increased gradually. The grain size of pure $\mathrm{Ni}_{0.5} \mathrm{Zn}_{0.5}$ $\mathrm{Fe}_{2} \mathrm{O}_{4}$ lies between 50-100 nm [Fig. 1(a)], while for $1 \mathrm{wt} \% \mathrm{CNT}$ composite, the grain size is five times that of CNT-free sample [Fig. 1(b)]. The grain size distribution in these two samples is relatively uniform. Abnormal grain growth could also be observed when the CNT amount increased [Fig. 1(c)]. At $5 \mathrm{wt} \%$ of CNTs, the grain size is greater than 1 micron. Compared with the sample of pure $\mathrm{Ni}_{0.5} \mathrm{Zn}_{0.5} \mathrm{Fe}_{2} \mathrm{O}_{4}$, the samples with CNTs have higher density (Table 1). The experimental results indicate that the introduction of the CNTs can promote the sintering kinetics of the ferrite ceramics.

Figure 2(a) represents XRD patterns of composites with different CNT contents. Both samples of $\mathrm{Ni}_{0.5} \mathrm{Zn}_{0.5} \mathrm{Fe}_{2} \mathrm{O}_{4}$ and 0.5
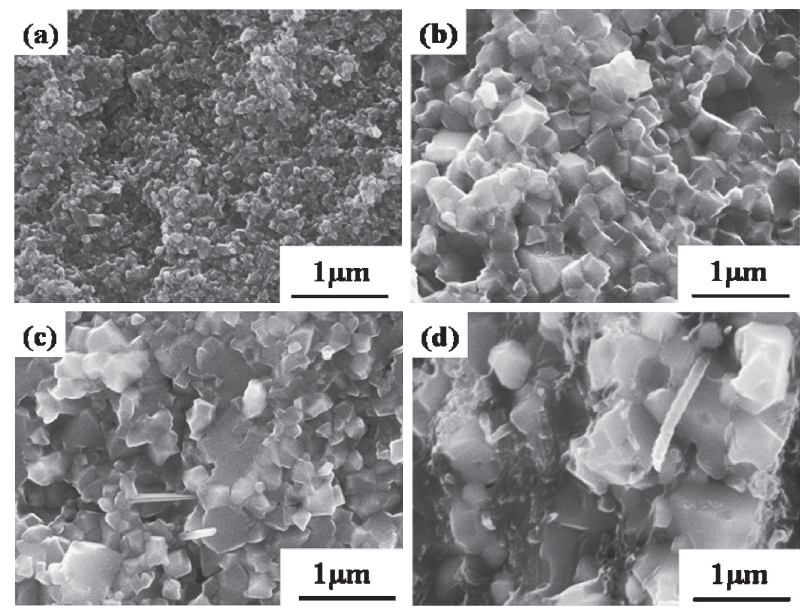

Fig. 1. SEM images of the fracture surface of samples containing (a) $0 \mathrm{wt} \%$; (b) $1 \mathrm{wt} \%$; (c) $2 \mathrm{wt} \%$ and (d) $5 \mathrm{wt} \%$ CNTs. All samples were fabricated by SPS at $800^{\circ} \mathrm{C}$ for $5 \mathrm{~min}$.

Table 1. Physical properties of composites fabricated by SPS at $800^{\circ} \mathrm{C}$ for $5 \mathrm{~min}$

\begin{tabular}{cccccc}
\hline \multirow{2}{*}{$\begin{array}{c}\mathrm{CNT} \\
\text { contents }\end{array}$} & \multirow{2}{*}{$\begin{array}{c}\text { Grain } \\
\text { size }\end{array}$} & $\begin{array}{c}\text { Density } \\
\left(\mathrm{g} / \mathrm{cm}^{3}\right)\end{array}$ & $\begin{array}{c}\mathrm{M}_{\mathrm{s}} \\
(\mathrm{emu} / \mathrm{g})\end{array}$ & \multicolumn{2}{c}{$\sigma\left(\mathrm{S} \mathrm{m}^{-1}\right)$} \\
\hline CNT-free & $75 \mathrm{~nm}$ & 4.965 & 71.41 & $3.48 \times 10^{-6}$ & $\mathrm{~N} / \mathrm{A}$ \\
$0.5 \mathrm{wt} \%$ & $400 \mathrm{~nm}$ & 5.224 & 76.49 & $4.36 \times 10^{3}$ & $1.00 \times 10^{-1}$ \\
$1 \mathrm{wt} \%$ & $500 \mathrm{~nm}$ & 5.193 & 81.21 & $1.14 \times 10^{4}$ & $6.30 \times 10^{-1}$ \\
$2 \mathrm{wt} \%$ & $600 \mathrm{~nm}$ & 5.227 & 86.89 & $7.00 \times 10^{4}$ & $8.81 \times 10^{1}$ \\
$5 \mathrm{wt} \%$ & $1 \mu \mathrm{m}$ & 5.065 & 18.43 & $9.11 \times 10^{4}$ & $1.15 \times 10^{2}$ \\
\hline
\end{tabular}

wt $\% \mathrm{CNT} / \mathrm{Ni}_{0.5} \mathrm{Zn}_{0.5} \mathrm{Fe}_{2} \mathrm{O}_{4}$ are composed of pure spinel phase, which characteristic diffraction peaks are well consistent with the standard JCPDS card NO.8-234. As the amount of CNTs increased to 1 and $2 \mathrm{wt} \%$, a new phase of $\mathrm{Ni}$ appeared; the $\mathrm{Ni}$ content increased with the CNT increment. Furthermore, as shown in the XRD patterns of the $2 \theta$ from 29 to 37 degree in Fig. 2(b), the positions of the (311) and (220) peaks shift to the lower-angle with the increasing of CNT contents. This shift was caused by the expansion of lattice cell due to the reduction of $\mathrm{Ni}$ ion from the $\mathrm{A}$ site of $\mathrm{Ni}-\mathrm{Zn}$ ferrite. The lattice parameters increased from 0.8383 to $0.8415 \mathrm{~nm}$, when CNT contents increment from 0 to $2 \mathrm{wt} \%$ (see Table 2). Although the characteristic diffraction peaks of $\mathrm{Ni}$ metal are not visible in the $0.5 \mathrm{wt} \%$ composite due to the detection limit of XRD technique, the peak shift of ferrite in Fig. 2(b) corroborates the liberation of $\mathrm{Ni}$ atoms from ferrite and the formation of $\mathrm{Ni}$ nanoparticles in the final product that visible in the BSE image (not shown here). During the nucleation and growth of $\mathrm{Ni}$ metal in the composites, the liquid state of $\mathrm{Ni}$ can act as sintering aid to accelerate the void elimination and grain boundary extension that well explain the grain growth and fully consolidation of ferrite composites as shown in Fig. 1.

Regarding to the phase stability of ferrite materials in the presence of carbon material and in the vacuum condition $(3 \mathrm{~Pa})$ during SPS sintering, the thermodynamic analysis is performed. Certainly, the analysis is just qualitative comparison among the carbothemal reductions of the nickel oxide, zinc oxide and iron oxide. The difference in the Gibbs free formation energy of the metal from carbothermal reduction of metallic oxide is the key driving force. For a given basic oxidation-reduction reaction, the Gibbs free energy of reaction can be calculated by subtracting the Gibbs free formation energy of all products from that of all reactants. The Gibbs free energy of carbothermal reduction of different oxides was calculated using as shown in Fig. 3 by representing the dependence of calculated Gibbs free energies of three possible reactions on the temperature ranging from 0 to $1000^{\circ} \mathrm{C}$. Obviously, The Gibbs free energy of metal formation decreases with the temperature increasing, and the transition points where carbothermal reduction reaction for nickel oxide, iron oxide and zinc oxide carbothermal reduction become thermodynamically favorable are at about 430,720 and $970^{\circ} \mathrm{C}$,

Table 2. Lattice parameter of $\mathrm{Ni}-\mathrm{Zn}$ ferrite in the composites with different CNT contents determined from the experimental XRD data

\begin{tabular}{ccccc}
\hline samples & CNT-free & $0.5 \mathrm{wt} \%$ & $1 \mathrm{wt} \%$ & $2 \mathrm{wt} \%$ \\
\hline Lattice parameters $a(\mathrm{~nm})$ & 0.8383 & 0.8394 & 0.8399 & 0.8415 \\
\hline
\end{tabular}
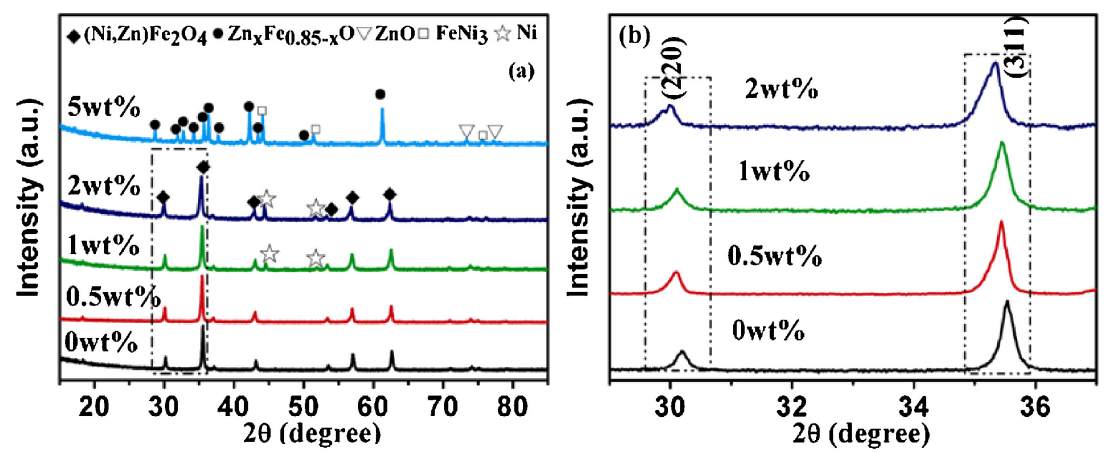

Fig. 2. (a) XRD patterns of pure ferrite and multiphase composites fabricated by SPS sintered at $800^{\circ} \mathrm{C}$ for $5 \mathrm{~min}$, and (b) XRD patterns of multiphase composites showing the peak shift phenomena. 


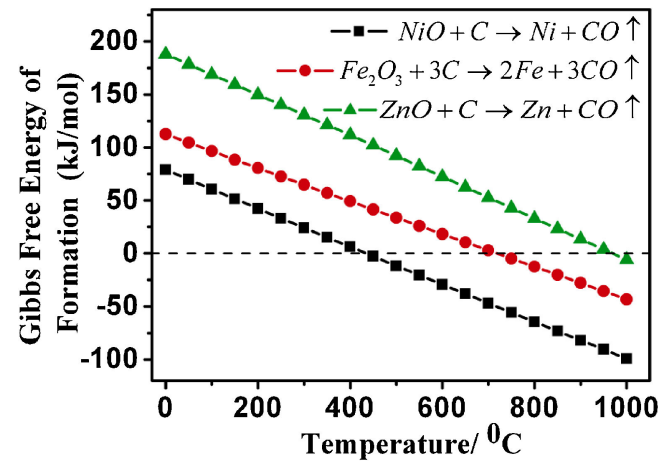

Fig. 3. Gibbs free energy of formation with temperature from 0 to $1000^{\circ} \mathrm{C}$.

respectively. That means the Ni metal will be first reduced, and then the $\mathrm{Fe}$ and $\mathrm{Zn}$ metals. Since the sintering temperature in current experiment was $800^{\circ} \mathrm{C}$, the condition is satisfied for the precipitation of both $\mathrm{Ni}$ and $\mathrm{Fe}$ metals. However, only $5 \mathrm{wt} \%$ sample show the presence of $\mathrm{FeNi}_{3}$ alloy phase in Fig. 2(a), and other samples containing low content of CNTs has seldom Ni phase as identified by XRD. When counting the formation energy of ferrite from these oxides, the transitive temperature will be high. From the crystal chemistry point of view, more energy is required for the $\mathrm{Fe}$ ion breaking out from ferrite crystal lattice than from its oxide one before it gains electrons from carbon (carbothermal reduction reaction). The abnormal formation of $\mathrm{FeNi}_{3}$ phase in the $5 \mathrm{wt} \%$ composite sintering at same condition is attributed to the distinct heating method of SPS technique which electrical current would promote the chemical reaction.

It is well known that, in the SPS sintering process, high density currents flowing through graphite dies heat up the powdered samples, by Joule heat, to a target temperature in several minutes. The current output (depending on the heating rate and power), is usually from one thousand to several thousand amperes. ${ }^{17)}$ Since most of the ceramic particles are poor electrical conductors, so the thermal energy is only absorbed from the surrounding heat source. In the sintering of composites containing less CNTs, most of heat was transferred from graphite die to the samples. However, the composites could become well conductive when the CNT network is formed at high concentration. ${ }^{18)}$ It is thus expected that part of the pulsed current would have flowed directly through the bulk materials and the conductive network provided an additional source of heating. Since the resistivity of CNTs $\left(10^{-4} \Omega \mathrm{cm}\right)^{17)}$ is much lower than that of ferrite particles $\left(10^{4} \Omega \mathrm{cm}\right)$, this branch current may pass mainly through the sidewalls of the CNTs, and the local temperature near CNTs should be much higher than that in ferrite grains as detected by outside optical thermometer. This local high temperature condition well explains the formation of $\mathrm{FeNi}_{3}$ alloy and eventually decomposition into $\mathrm{Zn}_{x} \mathrm{Fe}_{0.85-x} \mathrm{O}$ in $5 \mathrm{wt} \%$ sample. Thus, it is expected that the higher the content of CNTs in the composite ceramics, the more the ferrite matrix would be reduced or even decomposed such as in $5 \mathrm{wt} \% \mathrm{CNT}$ composite which include $\mathrm{FeNi}_{3}$ alloy, zinc oxide and Fe-scarce $\mathrm{Zn}_{x} \mathrm{Fe}_{0.85-x} \mathrm{O}$ ferrite in Fig. 2. Based on above results, it is crucial to control the content of CNTs in the ferrite to obtain the multiphase composites.

The temperature dependence of electrical conductivity of the $\mathrm{CNT} / \mathrm{Ni}_{0.5} \mathrm{Zn}_{0.5} \mathrm{Fe}_{2} \mathrm{O}_{4}$ composites with different $\mathrm{CNT}$ content is shown in Fig. 4. The electrical conductivity of $\mathrm{Ni}_{0.5} \mathrm{Zn}_{0.5} \mathrm{Fe}_{2} \mathrm{O}_{4}$ is only $3.48 \times 10^{-6} \mathrm{~S} / \mathrm{m}$ at room temperature, which displays a typical insulator properties. Obviously, with the CNT addition,

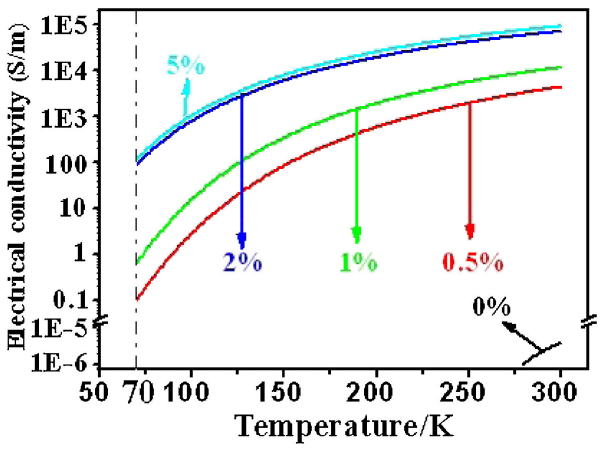

Fig. 4. Temperature dependence of electrical conductivity of bulks with different CNT contents sintered by SPS at $800^{\circ} \mathrm{C}$ for $5 \mathrm{~min}$.

the electrical conductivity significantly increased in a wide temperature range $(70-300 \mathrm{~K})$. The maximal achieved value of the electrical conductivity is $9.11 \times 10^{4} \mathrm{~S} / \mathrm{m}$ for the samples of $5 \mathrm{wt} \%$ composite at $300 \mathrm{~K}$, which is improved of ten orders of magnitude compared with pure $\mathrm{Ni}_{0.5} \mathrm{Zn}_{0.5} \mathrm{Fe}_{2} \mathrm{O}_{4}$ ceramics. When the temperature decreased, the electrical conductivity gradually decreased, thus exhibiting the characteristic semiconductor behavior. When the temperature dropped to $70 \mathrm{~K}$, the electrical conductivity of $5 \mathrm{wt} \%$ composite even remained at $1.15 \times 10^{2}$ $\mathrm{S} / \mathrm{m}$. It has been widely reported that due to the formation of three-dimensional conductive network along the grain boundaries, the addition of CNTs can effectively improve the electrical conductivity of ceramics. ${ }^{8), 99,18), 19)}$

\section{Conclusions}

Ferrite multiphase/carbon nanotube composites were fabricated by SPS technique. CNTs acted as "heating source" in the SPS process and promoted the sintering kinetics. Ni nanoparticles can in situ form in the composites through carbothermal reduction reaction. The three-dimensional conductive network of CNTs was well retained to keep the reasonable conductivity. The electrical conductivity was significantly dependent on the CNT content in the composite materials, compared with CNT-free sample, the electrical conductivity of $5 \mathrm{wt} \%$ composite has increased of ten orders of magnitude at $300 \mathrm{~K}$.

Acknowledgements This work was financially supported by 'Hundred Talents Programme' of The Chinese Academy of Sciences (KJCX2-EW-H06), Technological research fund for the public welfare of Zhejiang province (Grant NO.2012C21017).Ningbo Natural Science Foundation (Grant No. 2013A610131), National Natural Science Foundation of China (Grant No. 51172248 and 11005120), State Key Laboratory of Porous Metal Materials (PMM-SKL-1-2013). This research was supported by a Yeungnam University research grant in 2014.

\section{References}

1) A. Verma and D. C. Dube, J. Am. Ceram. Soc., 88, 519-523 (2005).

2) J. Azadmanjiri, Mater. Chem. Phys., 109, 109-112 (2008).

3) M. P. Reddy, W. Madhuri, N. R. Reddy, K. S. Kumar, V. Murthy and R. R. Reddy, J. Electroceram., 28, 1-9 (2012).

4) A. Costa, E. Tortella, M. Morelli, M. Kaufman and R. Kiminami, J. Mater. Sci., 37, 3569-3572 (2002).

5) A. S. Albuquerque, J. D. Ardisson, W. A. A. Macedo and M. Alves, J. Appl. Phys., 87, 4352-4357 (2000).

6) S. Iijima, Nature, 354, 56-58 (1991).

7) L. Jiang and L. Gao, Chem. Mater., 15, 2848-2853 (2003). 
8) Q. Huang and L. Gao, Appl. Phys. Lett., 86, 123104 (2005).

9) X. B. Zhou, L. Shen, L. Li, S. H. Zhou, T. M. Huang, C. F. Hu, W. M. Pan, X. H. Jing, J. Sun and L. Gao, J. Eur. Ceram. Soc., 33, 2119-2126 (2013).

10) E. T. Thostenson, Z. Ren and T. W. Chou, Compos. Sci. Technol., 61, 1899-1912 (2001).

11) Y. Q. Liu and L. Gao, Carbon, 43, 47-52 (2005).

12) M. Han and L. Deng, Appl. Phys. Lett., 90, 011108 (2007).

13) J. Snoek, Physica, 14, 207-217 (1948).

14) V. B. Bregar, IEEE Trans. Magn., 40, 1679-1684 (2004).

15) X. F. Zhang, X. L. Dong, H. Huang, Y. Y. Liu, W. N. Wang,
X. G. Zhu, B. Lv and J. P. Lei, Appl. Phys. Lett., 89, 53115 (2006).

16) J. J. Sun, J. B. Li, G. L. Sun and W. G. Qu, Ceram. Int., 28, $855-858$ (2002).

17) Q. Huang, D. Jiang, I. Ovid'Ko and A. Mukherjee, Scr. Mater., 63, 1181-1184 (2010).

18) G. D. Zhan, J. D. Kuntz, J. E. Garay and A. K. Mukherjee, Appl. Phys. Lett., 83, 1228-1230 (2003).

19) F. Inam, H. Yan, D. D. Jayaseelan, T. Peijs and M. J. Reece, J. Eur. Ceram. Soc., 30, 153-157 (2010). 